\title{
La mediación penal en caso de incesto
}

\section{Diana Regalado Hidalgo*}

\section{Resumen}

En su gran mayoría, los casos de incesto no se develan, la situación abusiva se repite de una forma u otra y la niña queda encerrada en su terrible secreto. Por otro lado en los escasos casos que pasan a mano de la justicia, el padre está botado en una cárcel donde suele estar maltratado por los otros presos, y la niña vive una culpabilidad intensa por este mismo hecho.

La mediación penal, un proceso judicial llevado a cabo bajo la responsabilidad de un fiscal, permite, sin ocuparse de dictar sanciones, restablecer una relación de palabras entre la hija y su padre, y de este modo ayudar a una re-inscripción de ambos en una sociedad fundada en la Ley Universal de Prohibición del Incesto.

\section{Palabras clave}

Mediación penal, incesto, proceso restaurativo, violencia sexual, familia.

\section{Abstract}

The cases of incest, most of the times, are not unveiled; the situation of violence and permanent abuse is used to taking place very often, it makes in one way or another the girl remain caught in her terrible secret and hide it for a long time. On the other hand, in the few cases that go to the justice process, the father is lockedup in a prison where he gets permanent maltreatment from the other prisoners, and the girl, victim of incest is used to feeling an intense guiltiness due to this fact.

The penal mediation, a judicial process carried out under the responsibility of a public prosecutor, allows - without dictating any sanctions- to reestablish a relationship between the father and the daughter, in order to help the reinsertion of both in a society founded on the Universal Law of Incest Prohibition.

\section{Key words}

Criminal mediation, incest, restorative process, sexual violence, family.

Forma sugerida de citar: Regalado Hidalgo, Diana. 2010. La mediación penal en caso de incesto. Univesitas 13, Julio/diciembre. Pp. 131-154.

Psicóloga Clínica (PUCE). Dirige la unidad de atención a las víctimas en la Fiscalía Provincial de Pichincha. Quito-Ecuador 
La mayoría de los casos de incesto no son denunciados ante la ley, y aquellos que lo son revictimizan y maltratan a las víctimas o no concluyen en una sentencia, dejando al padre abusador impune, a la familia destrozada y a la niña a su suerte. La mediación penal que es uno de los procedimientos penales posibles parte de la premisa de que se está tratando con sujetos, no con penas, dando por lo tanto, importancia a la subjetividad, a la alteridad y cabida a la historia personal de cada uno. Es un espacio que compromete a cada uno de los involucrados en la relación incestuosa, en el proceso con responsabilidad, haciendo que la solución al conflicto sea asumido por todos y por lo tanto, se evite la reincidencia. Este tipo de proceso alternativo y restaurativo, al ser parte del ámbito penal, viene a enunciar y a inscribir por primera vez, a esta niña y a su padre, en un registro hasta ahora desconocido por ellos: la Ley de Prohibición del Incesto. Por otro lado, la mediación penal abre la posibilidad a la familia incestuosa de re-estructurarse sanamente, de re-construir nuevos lazos afectivos y vínculos sanos entre sí y con el resto de la sociedad, de la cual estaban aislados. Este tipo de procesos permite que la palabra de la niña, víctima de incesto, tenga efectos, pero sin que ésta sea sentida como demasiado peligrosa o traicionera, lo que permitiría que muchos casos de incesto, que quedan normalmente en secreto por miedo a las sanciones jurídico-penales que conllevaría su develamiento, sean denunciados y puedan ser tratados adecuadamente.

Es importante encontrar nuevas alternativas a la justicia penal tradicional que nos permitan abordar este tipo de casos, sin necesariamente anular o excluir a los sujetos, incluso aquellos que nos parezcan los más monstruosos y que causan en nosotros el mayor rechazo.

El abuso sexual infantil es una de las problemáticas con mayor incidencia en nuestro país y a nivel mundial, no se restringe a un grupo de personas determinado y es una realidad social que afecta a todas las clases socioeconómicas. Dentro de los tipos de abuso sexual, el incesto1 es una de sus variantes con mayores consecuencias, ya que no sólo afecta a la niña abusada, sino que alcanza a

$1 \quad$ Al ser el tema del incesto bastante amplio, el presente artículo se limitará a abordar únicamente el incesto padre-hija ya que es su variable mas común de entre todas las demás relaciones incestuosas que pueden existir dentro de una familia (incesto padre-hijo, madre-hijo/a, entre hermanos y entre abuelos/as -nietos/as). 
toda la familia, núcleo en el que se encuentran tanto la víctima como el victimario. El incesto da cuenta de una anomalía a nivel familiar y social, que implica la trasgresión y anulación de una ley fundamental: La Ley de Prohibición del Incesto; la misma que organiza todo grupo social, determinando permisos, prohibiciones, funciones y separando generaciones.

El incesto es considerado un agravante del abuso sexual y es penado por la ley como tal, lo que implica largos procesos judiciales, encarcelamiento y pérdida de la patria potestad para el padre o madre abusadores. Estos procesos traen consigo graves consecuencias legales, sociales y psíquicas en el autor del incesto, siendo mucho más profundas las consecuencias, en los mismos ámbitos, en la niña abusada y en su familia, ahondando aún más en la crisis que se vivía ya con el incesto. Sin embargo, el incesto es tomado como un agravante de un delito sexual como los otros por las implicaciones que conlleva a nivel individual y familiar, por lo tanto, no debe ni puede ser tratado como el resto de abusos sexuales. Los métodos judiciales comunes aplicados hoy en día en casos de incesto no funcionan adecuadamente, y fallan, generalmente, en su misión de instauración de dicha ley, lo que deteriora aún más la desestructuración familiar que ya trae consigo una situación de incesto. Las penas aunque necesarias, son generalizadoras y no alcanzan siempre, o casi nunca, sus objetivos: rehabilitar y re-insertar socialmente al infractor. Lograr fundamentar una alternativa más justa y humana a los procesos judiciales penales, que logre analizar la problemática de cada caso más profundamente, tomando en cuenta a esa familia incestuosa y las relaciones que dentro de ella existen y la hacen distinta de las demás, es un deber ético y moral que reclama urgencia. Para el efecto existe una alternativa de atención y seguimiento más personalizados a los procesos penales y que busca evitar la dureza de la justicia tradicional: la mediación penal, que basada en lo que se conoce actualmente como justicia restaurativa, logra disminuir los efectos negativos de un proceso penal y permite, tanto a la víctima, como a la familia y al padre incestuoso, salir lo menos perturbados posible de esta situación tanto en el ámbito jurídico como en el psicológico.

El introducir un tema complejo y de alto impacto social como este, no apunta a reformular ninguna ley jurídico penal ecuatoriana, pero si a plantear interrogantes y cuestionamientos acerca de los efectos psíquicos que tienen las 
medidas penales actuales en las víctimas del incesto, sobre todo en estas niñas a quienes se revictimiza reiteradamente en cada etapa del procedimiento penal, y abordar las ventajas, que a nivel psíquico, podría tener una mediación penal aplicada técnica y profesionalmente, que redundaría en que el menor afectado y demás integrantes de la familia puedan beneficiarse psicológicamente de este proceso alternativo, minimizando el riesgo de recaer en una situación de abuso. Se intenta plantear a la mediación penal en su posibilidad, aunque hipotética, de ser una instancia de carácter jurídico que, a cargo de un equipo de profesionales, se constituya como una herramienta que le permita a la niña abusada salir poco a poco del silencio mortífero y cruel que causa el delito sexual agravado por incesto y además permita (re)instaurar esa ley simbólica y socialmente aceptada, de prohibición del incesto, logrando así la reinserción de la familia dentro de las leyes y normas socio jurídicas del país, que tienen como base esta ley primordial. Antes de iniciar el abordaje de esta temática, es importante aclarar que la mediación penal es un procedimiento judicial alterno y no es, ni pretende ser en ningún momento un proceso terapéutico; sin embargo, al estar basada en una dialéctica de la palabra, la mediación penal puede lograr efectos de este tipo, alivianando la carga psicológica que trae consigo el incesto en cada una de las partes implicadas.

\section{El secreto y su develamiento: el poder de la palabra}

El incesto entre un padre y su hija es a menudo una situación que se da en silencio durante varios años antes de ser conocida por un tercero, sea este un miembro de la familia (madre de la niña, hermanos, abuelos, tíos), una persona del entorno social del menor (profesora, educadora, psicóloga, vecinos, amigos de la familia) o una instancia social o legal.

Muchas ocasiones, el incesto es un secreto compartido pero 'impuesto' por uno de sus protagonistas, que de manera general suele ser el padre. El secreto del incesto, al ser compartido y por la reciprocidad que instaura y mantiene, crea un lazo poderoso y permeable entre ambas partes. Este secreto además de ser impuesto a la niña desde el exterior, es decir por el padre abusador, le es también impuesto desde su interior por un estado de sideración psíquica que constituye un modo defensivo contra la angustia de venganza materna y 
de pérdida total de los objetos amados. Este secreto de la relación padre - hija suele aparecer de una forma velada en el mismo sistema familiar, este secreto conlleva una prohibición de verbalizar las cosas e inclusive de pensarlas y esta prohibición puede ser explícita, pero la mayoría de veces es implícita y compartida por todos los miembros de la familia, y la interdicción de mencionar el incesto recae igualmente en todos aquellos que la conforman. En efecto, es el secreto sobre las relaciones incestuosas dentro de la familia lo que la mantiene unida, por un lado generando los vínculos y relaciones entre unos y otros, y manteniéndola aislada del resto de familias y sociedad por el otro; en estas familias no es el incesto el que está prohibído sino el mencionarlo. El secreto crea complicidad entre los que lo comparten, por un lado logra convencer a la víctima que está siendo privilegiada por su padre frente a los demás miembros de la familia, pero por el otro le permite tener cierto poder sobre el victimario ya que tiene la posibilidad de hablar y develar en cualquier momento la situación de incesto y poner en tela de juicio las actitudes de este último.

En algún momento, en un contexto de enorme sufrimiento y de terror pero igualmente de la existencia de un tercero protector $^{2}$, se forma en la víctima una consciencia más o menos clara de la existencia de una ley social diferente a aquella impuesta por sus progenitores dentro del sistema familiar que le va a dar la posibilidad de hablar a alguien del incesto que sufre. El develamiento es ciertamente un acto de liberación, pero este acto se convierte al mismo tiempo en una acusación que puede llevar a su padre frente a la justicia e incluso a la cárcel, lo que genera un impacto adicional en la ya afectada psiquis del menor: “...si el incesto le convertía culpable de traición hacia su madre, lo que revela o de lo que da testimonio le convierte en culpable de meter a su padre en la cárcel, con todas las graves consecuencias afectivas y socio-económicas para la familia" (Criville, 1996: 191).

De hecho, la niña imagina que denunciar a su padre va a conllevar a su consecuente pérdida e inducir catástrofes peores que el incesto mismo tanto para

2 Cuando hablamos de un tercero protector estamos haciendo referencia a un tercero en la relación dual padre-hija generada con el incesto, que esta sea representada por una o varias personas, una instancia social o legal, en la que la niña deposita su secreto y confianza y cuya función principal es poner un alto a la situación de incesto. 
ella como para su familia a la que se siente en obligación de proteger, en efecto, los sentimientos hacia su padre incestuoso son ambivalentes y que su padre vaya a la cárcel incluso si se lo odia (y ama) es una responsabilidad que a pesar de que le corresponde al sistema de justicia juzgar y condenar, es muy dura de asumir para una niña o adolescente. Esta situación cargada de ambivalencia conduce muchas veces a pasajes al acto graves como tentativas de suicidio, fugas, y delincuencias. El develamiento del incesto es un tiempo de ruptura, que conduce a una crisis de la familia ya que pone en duda su organización y su función como instancia protectora; esta reaccionará a partir de la negación y el rechazo del agente que produjo la crisis, es decir del menor abusado. El develamiento es un momento crucial que puede presentar un riesgo de traumatismo suplementario a la situación de incesto para la niña o adolescente, es una etapa que no necesariamente va a lograrse de modo inmediato, sino a través de pequeños y varios intentos: "El niño/a, o bien buscará llamar la atención del adulto por síntomas más o menos discretos a ser descifrados por un adulto perspicaz, o bien lo hará con sus propias palabras" (Gabel, 2007: 121). Algunos de estos síntomas pueden ser la enuresis, encopresis, pesadillas y terrores nocturnos, agresividad, rebeldía, dolores abdominales frecuentes, manipulación compulsiva de los genitales, juegos de tipo sexual.

El develamiento permite que la palabra se haga posible, pero esto no quiere decir que se hace inmediatamente accesible a aquellos a la que está dirigida, porque implica que ese tercero al que la niña habla y cuenta su situación represente realmente lo que la niña busca: que sea una herramienta para poner alto a la situación de incesto. Si tanto el padre, la niña como el resto de los miembros de la familia tuvieran la posibilidad de parar y salir de la situación de incesto que no sea tan devastadora como la justicia penal tradicional, muchos de estos casos serían denunciados y tratados, evitando toda la carga emocional de temores y consecuencias que esto trae. Para que la niña pueda hablar es necesario que su palabra no sea sentida, por ella misma, como muy peligrosa o que, a su parecer, contenga un mal más grande que el ya vivido. Después de haber revelado la situación de incesto muchas veces la víctima no tiene credibilidad y no es escuchada, tiene que hacer frente a diferentes consecuencias, como el temor de lo que pasará con su padre, su ausencia, la ruptura familiar generada por el conocimiento del incesto, el rechazo y negación por parte de los demás 
miembros de la familia, y lo más importante: la culpabilidad. Por ello y frente a todas estas dificultades la niña siente que no tiene más opción que retractarse de lo que dijo, la retractación es considerada como la adaptación extrema a la situación incestuosa ya que busca un regreso a la situación anterior de silencio, a un modo de funcionamiento anterior que parece a veces menos violento, menos terrorífico que la situación nueva, en la que se ha perdido confianza en las propias palabras.

\section{Medidas judiciales y sanciones penales actuales y sus efectos}

El código penal y el código de la niñez y adolescencia no tienen un artículo que hable del incesto específicamente, sin embargo dice al respecto el artículo 514 del capítulo segundo, del Título VIII de los delitos sexuales: "Del atentado contra el pudor, de la violación y el estupro" del Código Penal del Ecuador, toma al incesto como un agravante del delito de violación (tipificado en el artículo 512 del mismo capítulo); así, es violación:

El acceso carnal, con introducción total o parcial del miembro viril, por vía oral, anal o vaginal; o la introducción, por vía vaginal o anal, de los objetos, dedos u órganos distintos del miembro viril, a una persona de cualquier sexo, en los siguientes casos:

1. cuando la víctima fuere menor de catorce años

2. cuando la persona ofendida se hallare privada de la razón o el sentido, o cuando por enfermedad o por cualquier otra causa no pudiera resistirse; $y$,

3. cuando se usare de violencia, amenaza o intimidación (Código Penal, 2008).

Si las víctimas son sus descendientes, ascendientes, hermanos o afines en línea recta, el delito de violación es sancionado con reclusión mayor especial de 16 a 25 años más pérdida de la patria potestad (ibíd). A pesar de que la violación consta en el Código Penal Ecuatoriano como un tipo de delito sexual (abuso sexual) entre los que también se encuentran el estupro y el atentado contra el pudor, el Código de la Niñez y Adolescencia, sin perjuicio de lo que 
dispone el Código Penal sobre la materia dice sobre lo que constituye el abuso sexual: “...todo contacto físico, sugerencia de naturaleza sexual, a los que se somete un niño, niña o adolescente, aún con su aparente consentimiento, mediante seducción, chantaje, intimidación, engaños, amenazas o cualquier otro medio"(Código de la niñez y adolescencia, 2007), y es sancionado con las penas antes mencionadas. De ahí que todo contacto físico, desde caricias hasta aquellos contactos que impliquen penetración o cualquier sugerencia de naturaleza sexual a los que cualquiera de los dos progenitores somete a su hija o hijo, un padre somete a su hija es considerado incesto y es castigado con reclusión mayor de 16 a 25 años, más la pérdida de la patria potestad sobre el menor. Es importante recalcar que no se trata aquí de aceptar o rechazar el encarcelamiento del padre sino de evaluar las ventajas y desventajas, que en una realidad tan común como es el incesto en nuestro país, conllevan las medidas jurídicas tradicionales. El incesto padre-hija es penado con el encarcelamiento del padre por un tiempo mínimo de 16 y un máximo de 25 años, más la pérdida de la patria potestad de su hija, es decir, la pérdida del:

...conjunto de derechos y obligaciones que la ley reconoce a los padres sobre las personas y bienes de sus hijos mientras estos son menores de edad o están incapacitados, con el objetivo de permitir un cumplimiento a aquellos de los deberes que tienen de sostenimiento y educación de tales hijos ${ }^{3}$.

Sin embargo, a pesar de que el distanciamiento del padre de su hija permite hacer un alto necesario al incesto y que parecería que el encarcelamiento d e 1 padre brinda esta solución, no es garantía de un final al escenario de terror y angustia que vive la niña. De hecho, el encarcelamiento del padre conlleva graves efectos tanto para la niña como para la familia, incluso a veces más difíciles de soportar que la situación de misma de incesto. 
Como se explicó antes, con el develamiento del incesto ante una instancia jurídica, se inicia un procedimiento penal que concluiría, en el mejor de los casos, con el encarcelamiento del padre, muchas veces inesperado para la niña. Buscará parar la situación de incesto pero no necesariamente el encarcelamiento de su padre, a quien teme por lo que hace pero a quien también ama; con las medidas judiciales actuales, la niña tiene que hacer frente a un intenso sentimiento de culpabilidad al sentirse responsable, por mandar a su padre a la cárcel, hacer frente al resto de la familia que la culpa por ello y el haberlos dejado sin un padre presente, principal sustento económico del hogar. Además, el hecho de que el padre se encuentre presente en el hogar o encarcelado no lo exime de su lugar dentro de la familia: el poder que tenía sobre su entorno familiar puede quedar intacto, su función dentro de la familia sigue siendo real a pesar de no tener presencia física en ella. El incesto es una situación que va más allá de la presencia o ausencia del padre abusador, es un problema a nivel de las relaciones no sólo entre padre e hija sino entre todos los miembros de la familia. Es un problema de inscripción en la ley, inscripción que falla en ese hogar y que el encarcelamiento del padre, si no viene acompañado por un proceso terapéutico a nivel familiar, no soluciona nada, por el contrario trae más problemas. Por este motivo, cuando el padre cumple su condena, si es que llega a cumplirla, y retorna al seno familiar, el riesgo de reincidencia es enorme; en estos casos existen más peligros y vulnerabilidad después del encarcelamiento del padre que antes de él.

El encarcelamiento del padre puede desencadenar un trauma suplementario para la niña o adolescente incestada; para revelar el incesto es necesario que su palabra no sea sentida como muy peligrosa o que conlleve un mal más grande que el incesto mismo; no obstante, esta seguridad necesaria para la niña que cuenta su experiencia, se vuelve casi imposible con las medidas judiciales penales con que se trata actualmente el incesto, no sólo por el hecho de que el denunciar a su padre, podría llevarlo a la cárcel, sino por todos los procesos a los que está sometida esta niña al hacerlo: tiene que relatar varias veces y ante personas diferentes, -generalmente poco calificados- para tratar el asunto, relatar la historia, precisar detalles muy dolorosos de ser recordados, ser sometida a un examen médico legal que, si no es correctamente realizado ni explicado, puede representar una nueva invasión y agresión a su cuerpo y su privacidad 
(de ahí la importancia de la implementación de métodos menos invasivos como la entrevista única en cámaras de Gesell). El encarcelamiento es la aplicación de una pena por haber delinquido, pero ésta es concebida como el derecho que tiene la víctima de castigar y afectar dolorosamente al criminal por haber transgredido la ley. No olvidemos que, en este caso, a quien la víctima 'castiga' a través del sistema penal es a su padre. Ahora bien, la pena tiene como función hacer emerger en el padre un sentimiento de culpabilidad y responsabilidad, sin embargo, el encarcelamiento de éste, al no estar acompañado de un trabajo de rehabilitación, no permite una comprensión, ni mucho menos una responsabilización de la falta cometida. Con el encarcelamiento del padre incestuoso, el sistema penal busca protegerlo de la posibilidad de volver a abusar de esta hija o de cualquier otra persona, no obstante, más que una protección a la víctima y al infractor mismo, este encarcelamiento es la manera que encuentra el Estado para neutralizarlo y sacarlo de circulación, y no una posibilidad para este sujeto de re-estructurarse y re-integrarse sanamente en la sociedad. El problema de este tipo de medidas y sanciones penales es que no están acompañadas de ningún tipo de proceso terapéutico ni de rehabilitación que permita hacer de este padre ahora incestuoso, un padre estructurante, capaz de cumplir una función positiva en la vida de esta niña. En efecto, resulta muy difícil efectuar un tratamiento o terapia en prisión, en donde el recluso se siente a merced de la severa represión que tiene que vivir a diario o donde no tiene qué comer o dónde dormir, en un entorno poco amigable y atemorizante: "El tratamiento llevado a cabo en prisiones tradicionales es como enseñar deportes en un ascensor" (Neuman, 2005: 38).

El padre, en la cárcel, pierde la posibilidad de tomar consciencia de sus actos y de las consecuencias que éstos produjeron a su hija y a su familia, se convierte inmediatamente en alguien alejado y ajeno a su propio acto y responsabilidad sobre él. Ya en la cárcel, deja de ser culpable para pasar a ser víctima del sistema penal. De hecho:

Si la sanción no atraviesa nada de la subjetividad se torna no sólo inocua sino también peligrosa porque queda planteada como una simple venganza social contra alguien que no puede dar significación alguna ni a su acto ni a la pena por el acto; y entender la pena como una venganza 
injusta es la vía más rápida y simple a la 'auto desculpabilización', y luego de la cual no es improbable que el iter criminis recomience (Neuman, 2005: 34).

Por otra parte, los procedimientos jurídico-penales actuales en Ecuador, se centran en el padre abusador y dejan de lado a la niña y sus necesidades. Al denunciar el incesto, la niña o adolescente pide auxilio, protección, pero principalmente, pide ser escuchada y comprendida; sin embargo, lo que encuentra son más abusos y maltratos por parte de los adultos que son parte del sistema jurídico, y se convierte únicamente en aquello cuyo testimonio es fundamental para sentenciar al padre, que es lo que finalmente busca el sistema penal.

A esta niña o adolescente no le interesa hacer justicia imponiendo una pena al padre que abusó de ella, sino resarcirse del daño que éste le ha causado y, sobre todo, lo que desea es que su padre reconozca sus acciones. Es por otra parte importante recalcar, que lo más doloroso para la víctima es que el culpable no reciba sentencia alguna (de cualquier tipo) y esto es muy frecuente dado lo inoperante que es el sistema judicial actual en nuestro país, la mayoría de los juicios prescriben y más del 95\% de los casos en Latinoamérica quedan sin sentencia. (Neuman, 2005: 34)

\section{Ventajas de la mediación penal en caso de incesto}

Una mediación penal en caso de incesto es un proceso largo y que exige mucho trabajo y elaboración por parte de las personas implicadas en el conflicto. Para iniciar un proceso de mediación es primeramente necesario que la víctima y la familia hayan aceptado comenzar un diálogo con el padre incestuoso, esté o no en la cárcel, y que todos sus participantes comprendan el objetivo, los riesgos y condiciones de la mediación. Después de ser acordado entre las partes, un proceso de mediación en caso de incesto debería iniciarse con encuentros individuales con cada una de las personas involucradas en esta relación, con el objetivo específico de realizar una exploración preliminar de las expectativas, temores y necesidades de cada uno, así como de tener una comprensión del problema y significarlo en su historia propia y en la historia del otro. De modo que el trabajo de mediación en casos de incesto debe ser concebido como un pro- 
ceso de varias sesiones y no únicamente una sesión en la que se firma y cierra el acuerdo de mediación. Es importante recordar nuevamente que el proceso de mediación no es un proceso terapéutico, a pesar de que sí logra efectos de este tipo en sus participantes. La mediación podría desembocar y concluir -sería uno de los principales puntos planteados en el acuerdo final- en la continuación de un proceso terapéutico tanto para el menor abusado sexualmente y la familia iniciado antes del proceso de mediación como tal y un trabajo psicológico profundo para el responsable del delito. Es fundamental recordar a las partes que éste tiene como fin la elaboración de un contrato entre las partes que son compromisos y promesas que se hacen con el objetivo de darle un final satisfactorio al conflicto, compromisos que deben ser cumplidos con total responsabilidad y al pie de la letra y estar sometidos a un estricto seguimiento y vigilancia.

\section{La restitución de la palabra en el proceso de mediación}

Después de largo tiempo de silencio frente a la relación incestuosa, el proceso de mediación otorga la posibilidad a esta niña de restituir su palabra y de revalorizarla; el hablar por primera vez de los hechos sin negarlos ni ocultarlos, por una parte le otorga la posibilidad de significar lo vivido y ponerle palabras, y por otra da al padre la oportunidad, muy necesaria, de escuchar el otro lado de la historia, las consecuencias, sentimientos y efectos que sus actos produjeron. El proceso de mediación intenta hacer formular lo no-dicho hasta ese momento, que enmascara necesidades, temores, sentimientos, y expectativas tanto en el padre como en la niña. Entre la niña inocente, involucrada en un crimen que no cometió y entre el adulto incapaz de respetar el bienestar psíquico de su hija, la incomprensión es total ya que las palabras no tienen la misma significación para el uno y para el otro, la confusión de lenguas reina. En este contexto, la mediación busca crear una lengua en común para hablar de aquello que nunca antes se había hablado. En efecto,

...el proceso judicial ofrece un escaso marco para la palabra de los protagonistas. El discurso de las partes, a su vez, aparece traducido por sus letrados y muy difícilmente quedará registrado con alguna espontaneidad, porque forzosamente el lenguaje técnico opaca la frescura de los prota- 
gonistas (...) la mediación aparece como un espacio de mayor plenitud para la palabra (Arechaga, 2005: 176).

Así mismo, la mediación intenta re-crear un lazo social, un intercambio entre las partes a través de la comunicación, dando importancia fundamental a la palabra del otro, devolviéndole su lugar en cada uno, en el vínculo entre ellos y en relación a un tercero: el mediador, la familia, la sociedad, la ley.

\section{El trabajo de mediación con el padre incestuoso}

No se puede juzgar a un hombre sin interrogar su vida interior, ya que el acto, el acto delictivo o cualquier acto está intimamente vinculado con la discursividad del ser humano, ésa que le permite sostener un debate interno y con la alteridad del otro social. (Arechaga, 2005: 188).

Inicialmente, el padre incestuoso relata una historia en la que de cualquier manera se siente ajeno e incluso a veces víctima; él no se siente culpable, motivo por el cual alguna vez fue un padre incestuoso; lejos de reducirlo a la imagen diabólica de un psicópata criminal, lo que sería encasillarlo e imponerle un idioma que no entiende, la mediación intentaría en un primer momento facilitarle su idioma, por el cual podrá decir un poco de su historia y de su alienación. Al escuchar lo que este padre incestuoso tenga que decir, se le está dando la oportunidad de que se vuelva responsable de sus acciones y sepa y comprenda las consecuencias que el incesto produjo a su hija. Sólo es posible vincular al padre incestuoso con su acto si la culpabilidad se acompaña de responsabilidad, es decir si este puede subjetivizar la culpa y asignar significación a su acto, este paso de ser completamente ajeno a sus actos a hacerse responsable de ellos, es un trabajo a ser realizado, principalmente, en las primeras sesiones individuales del proceso de mediación con este padre.

Por otro lado, es importante durante el trabajo de mediación con el padre incestuoso, no olvidar que a pesar de los actos horrorosos que cometió con su hija, es aún su padre, incluso si legalmente ha perdido sus derechos como tal, no se trata aquí de hacer de la niña una hija huérfana, sino más bien de otorgarle la posibilidad a este padre, en la medida de lo posible, de volver a ser una 
figura estructurante y funcional en la construcción subjetiva de esta niña. En la mayoría de padres incestuosos, el acto incestuoso encuentra su explicación a partir de la relación que tiene el sujeto con la Ley de Prohibición del Incesto, el trabajo de mediación consistiría en (re)instaurar la ley en este padre, la que, si tomamos en cuenta la historia personal de este sujeto, no ha sido lo suficientemente edificada y lo ha llevado a la delincuencia. Con el incesto, el padre no asume su rol de protector y garante de la ley: el acto incestuoso lo ha despojado de su función simbólica ${ }^{4}$. La mediación, al ser un espacio enmarcado en la ley, intentaría iniciar la re-construcción de este lugar perdido y otorgarle la posibilidad de cristalizar, encarnar al padre simbólico responsable de la organización de la estructura inconsciente de esta niña y que haga valer la ley y disponga un acceso regulado al goce, elaboración que sería imposible sin un trabajo terapéutico posterior.

En última instancia, el trabajo de mediación con el padre incestuoso debería apuntar a que éste comprenda la transgresión en su acto y se involucre ética y moralmente en él y esto sólo es posible si lo escucha de boca de su víctima. El proceso de mediación implicaría para el padre la generación de un nuevo discurso más personalizado y en el que él se responsabilice. En efecto:

Si el sujeto asume en su discurso cuál es el lugar que le cabe en el banquillo de los acusados, es posible que asuma responsablemente sus faltas y se reintegre purgando sus culpas a la sociedad que lo condenó, si en cambio, expulsa de su discurso cualquier implicación subjetiva, y deja la punición a cargo de un juez y los aparatos sociales, no hace más que potenciar su acto criminal (Arechaga, 2005:192).

4 La paternidad remite a una compleja función. El psicoanálisis ha hecho de esto un tema complejo, diferenciando acertadamente al padre real, imaginario y simbólico, registros diferentes bajo los cuales se presenta la paternidad. El padre real es ese ser hablante de carne y hueso que embarazo a la madre y le dio un hijo. De este padre si está presente en la vida de esta niña, se esperan muchas cosas, entre ellas que tenga por función el cristalizar, encarnar al padre simbólico responsable de la organización de la estructura inconsciente de esta niña y que haga valer la ley simbólica de prohibición del incesto regulando el acceso al goce sexual, que es en última instancia la promesa de que cuando esta niña crezca, encontrara un hombre como su padre, fuera del seno familiar. 


\section{El trabajo de mediación con la niña}

La mediación penal, a diferencia de los procedimientos judiciales actuales, se centra en la víctima tomando en cuenta su experiencia, necesidades y miedos frente al incesto y a su padre. Sabemos, y esto ha sido demostrado hace ya varios años, que "...hasta qué punto el no reconocimiento de los hechos de una violación por el autor de éstos es un sufrimiento insoportable para la víctima. Ésta última lo vive como una segunda violación, esta vez de tipo moral" (Le Nail, 2008:195).

A la niña, más que hacer justicia, le interesa resarcirse del daño que su padre le hizo. El escuchar por su parte, primeramente un reconocimiento de los hechos ante ella y su familia, ante su madre y ante los profesionales encargados de llevar adelante el proceso de mediación, luego una explicación de los motivos que lo llevaron a actuar así y, sobre todo, que éste finalmente le pida perdón delante de más personas, lo que provoca efectos psíquicos positivos y da paso a un proceso de elaboración del trauma, aminorando así cualquier secuela que el incesto pudiera dejar, abriendo la posibilidad a un trabajo terapéutico futuro. En efecto, la niña no podrá liberarse de sus agresores internos si no es llevada a reconocer la realidad de sus padres y de los perjuicios que le hicieron sufrir, sólo este reconocimiento le podrá ayudar a dar un sentido a su vivencia y despojarse de su responsabilidad en el incesto. En teoría, la niña sabía de la Ley de Prohibición del Incesto, y siempre supo que algo en la relación con su padre no era correcto, sin embargo no podía hablar de esta prohibición; ya revelado el incesto, lo que la niña necesita es que la ley sea señalada para que tanto ella y en especial su padre puedan oírla, y el espacio de mediación, al ser un espacio formal y parte del ámbito legal, es un buen espacio para hacerlo. Un trabajo de mediación bien desarrollado apuntaría, a partir de diferentes sesiones y conversaciones, a que la menor abusada ponga en sus propias palabras la situación de incesto, la que hasta ese momento había sido marcada por un total silencio, palabras que van a ayudarla a dar un significado diferente al abuso y a integrarlo 
a su historia personal de la manera más sana posible, como la cicatriz de una herida curada.

Por otra parte, la niña llega a la mediación con una fuerte identificación con su padre, identificación que la convierte a ella en una persona mala, culpable de aquello que ha sucedido o que siente merecer. Con el acto incestuoso, la ley ha sido transgredida y esta trasgresión hace que se instale en ella un sentimiento de culpabilidad; el trabajo de mediación, la verbalización de la situación y la puesta en claro de la responsabilidad de los padres en el incesto rompe con las identificaciones ansiosas con el padre abusador y genera nuevos vínculos e identificaciones positivas con él. Además, esto facilita una comprensión por parte de la niña de su papel dentro de la situación de abuso al aceptar su condición de indefensión frente a la posición en la que el adulto la colocaba, así como la comprensión de que aquello que vivió, hizo o no dijo durante mucho tiempo fue lo que en ese momento, debido a su condición de indefensión, le permitieron hacer. El poner palabras sobre una situación traumática como el incesto, pero sobre todo el escuchar los motivos que llevaron a su padre a hacer lo que hizo, durante las sesiones de mediación, tiene efectos reparadores. La mediación al ser un espacio para la palabra, logra simbolizar de cierta manera el abuso y así darle una significación en la vida de esta niña permitiéndole salir del círculo vicioso de la repetición que se genera con el incesto. El hecho de restablecer los lazos afectivos y construir un vínculo diferente con su padre luego de un trabajo de mediación, permitiría junto con un trabajo terapéutico, reconstruir la relación a su deseo, su condición de mujer y la posibilidad de que a futuro pueda asumir roles familiares y de filiación.

Desde la primera sesión de mediación, este proceso puede ofrecer a la niña un espacio-tiempo necesario a la reflexión y a la confesión, es un lugar en el que puede expresar con toda confianza y seguridad respecto del abuso sexual, de su padre abusador, de su familia y de los hechos que se produjeron luego del develamiento. “... a partir de esto, la niña podrá más fácilmente recoger los pedazos y comenzar a reconstruir su imagen personal o el rompecabezas de su vida" (Haesevoets, 2008: 205). Este lugar para la palabra puede servir de base para iniciar un proceso largo y extenso de terapia. Es importante que se sienta protegida y así pueda volver a ver a sus padres, a su padre abusador, y que esté acompañada de su terapeuta con quien pueda luego trabajar individualmente y 
dentro de un encuadre diferente, los diversos temas abordados en el proceso de mediación.

\section{El trabajo de mediación con la familia}

El incesto es el síntoma de una disfunción en la estructura familiar, en las relaciones entre sus miembros y del poder que cada uno ejerce sobre el otro, en estas familias, la Ley de Prohibición del Incesto no opera como aquella que organiza y delimita las relaciones entre sus miembros, en estas familias los intercambios con el exterior están prohibídos, dentro de ellas, los hijos son tratados como posesión de sus padres y objetos del deseo de éstos; el padre es, a menudo, dominante, posesivo y celoso (y en otras ocasiones es una figura descalificada, anulada y rechazada por la madre) y la madre, generalmente, pasiva y sometida a las reglas del marido, en resumen, en estas familias, la ley de lenguaje, supuestamente universal, está recubierta por la intimidación, la anomia y por la ley del silencio, reforzada por todas aquellas amenazas explícitas e implícitas, confusiones y apatías. El incesto provoca un estallido de la estructura de parentesco en cuanto sistema nominativo, generando una ruptura en la diferencia generacional, no hay ni padre, ni madre, ni hija, ni hijo: no hay familia. La confusión de generaciones crea graves consecuencias en la subjetividad de cada uno pero sobre todo en el infante abusado que al estar en proceso de subjetivación necesita de unas figuras parentales claras. La situación incestuosa crea una evolución simétrica de la madre y la hija, provocando confusión, en especial, en ésta última de su lugar entre la pareja parental, la relación con sus hermanos y en cuanto a sus funciones dentro de la familia. En este marco, el incesto "...si su problemática no ha sido lo suficientemente elaborada y resuelta no parece tener sino dos salidas: hacer estallar la familia o aislarla del mundo de los otros" (Criville, 1998: 165).

El trabajo de mediación con estas familias consiste primeramente en detectar esas reglas intrínsecas de su funcionamiento para luego desarmar esta organización familiar patológica y reconstruirla a partir de una organización diferente en la que cada uno de los miembros de la familia tenga su lugar, su función y su rol bien definido. Dotar a este padre de una ley que le precede a él mismo (Ley de Prohibición del Incesto), a la madre permitirle una trans- 
formación de su relación a la ley en la medida en que se la podrá someter a la sugestión paradójica siguiente: continuar sometida a una ley pero esta vez con otro legislador, un legislador que funda el orden social y pasar de la ley tiránica de su marido, totalitario y dictador, a la ley democrática que es impuesta a ella como al resto de nosotros en relación a la prohibición y logar que pase de un rol pasivo que adoptó durante la situación de incesto a uno activo dentro de la familia; y en la hija y sus hermanos en el caso de que hubiera, hacer de ellos sujetos de derechos y deseos propios. La mediación y el mediador en sí, se convierten en esa instancia tercera que viene a hacer corte en esta relación enfermiza entre sus miembros, imponiéndoles una nueva ley (universal) diferente a la ley de la familia, generalmente impuesta por este padre.

El proceso de mediación al poner en claro la transgresión que se ha dado dentro de esta familia, pone en tela de juicio los lugares y roles que cada uno de los miembros de la familia venían ocupando dentro de ella, otorgándole a esta última, la posibilidad de reorganizar toda su estructura y sistema generacional, diferenciando así las funciones y roles de los padres y los roles y derechos de los niños, delimitando así mismo aquello permitido y aquello que por el contrario, está prohibído en la relación de unos con otros. El descubrimiento del incesto pone a la familia entera frente a un funcionamiento de sus relaciones que derrumban su estructura misma y la amenaza con excluirla definitivamente de la sociedad. Para poder hacer algo con ella dentro de un proceso de mediación, es necesaria que en un primer momento, la trasgresión sea reconocida:

Una prohibición, cuya carga simbólica toca las estructuras mismas del hombre social, no puede ser restituida en todo su valor sin explicar su sentido cuando es transgredida. La intervención tiene entonces esta primera significación: nomina la trasgresión y establece los hechos que la constituyeron (Criville, 1998: 164).

El objetivo principal del la mediación penal para la familia es hacer entender a todos los miembros de la familia que la niña fue víctima del incesto, que no tuvo ni tiene responsabilidad en lo acontecido, que su madre tuvo que haberla protegido y que es la obligación de todos evitar que vuelva a suceder. La mediación penal intentaría en un momento, consolidar y restaurar la integridad 
de todos los miembros de la familia y evitar futuros dilemas o recaídas. Finalmente, cabe señalar que ninguna familia se parece a otra en la manera en la que está estructurada afectivamente, económicamente y en la adjunción de roles, de ahí que la mediación penal toma en cuenta la unicidad e historia propia de cada familia y trabaja a partir de estas diferencias.

Uno de los puntos esenciales y fundamentales a ser tomados en consideración para entender la situación de incesto, y la relación dual, es el estatuto que tiene la niña en la relación que el padre incestuoso establece con ella. Crivillé menciona tres elementos distintos pero interdependientes que deben ser objeto de un examen clínico de evaluación y a ser considerados antes de iniciar un proceso de mediación: “...el tipo de organización de la personalidad del que inviste, el abusador, en relación al momento evolutivo de la organización de la personalidad de aquel que ha sido investido, el niño/a, y el sentido que la relación sexual entre los dos tiene para el uno y para el otro" (Criville, 1998: 97). Para esto, es importante no confundir los hechos con la experiencia subjetiva, lo manifiesto con lo latente y lo consciente con lo inconsciente. Tomemos en cuenta la importancia del 'lazo-relación' que va a modelar el desarrollo psíquico de la víctima del abuso, si bien es cierto que la relación con la madre es normalmente la primera y la fundamental en comparación con las demás que seguirán luego, “...la relación al padre viene a marcarla tempranamente por su posicionamiento en relación a la primera (con la madre) y repercute luego en las capacidades relacionales de la niña" (Criville, 1998: 97). En una relación de dependencia como la de padre-hija, ésta no puede ser investida libídinalmente sin ella reaccionar también por una investidura, así esto la perjudique. Así se instala entonces una dialéctica en la que la investidura del abusador por parte de la víctima será fuertemente marcada por las características de la relación que el abusador le impone. "La posición asimétrica padre-hija hace que el primero introduzca, a nivel de la seducción, una dinámica a la que la niña está obligada a reaccionar, y de cierta manera, de adaptarse para sobrevivir" (Criville, 2005: 98). Es precisamente este vínculo que un trabajo terapéutico, seguido de una mediación, debería desanudar. 


\section{El mediador como tercero en la relación dual padre-hija: re-instaura- ción de la Ley de Prohibición del Incesto}

Ahora bien, en el caso de una relación incestuosa entre padre e hija y ya analizada la relación entre el padre incestuoso es preciso entender el lugar que el mediador tiene dentro de ella. El mediador sin juzgar, permite desanudar el conjunto de hilos en este embrollo de sentimientos, resentimientos en medio de una situación muy compleja, considera todos los efectos de la separación y ayuda a encontrar nuevas soluciones, a considerar nuevos roles o una nueva forma de jugarlos, intenta hacer formular lo no-dicho, las necesidades e intereses de cada una de las partes, entre otros. Pero sin duda, su principal función dentro de la mediación es la de tercero, tercero en la relación entre las partes y, en el caso de incesto, en la relación dual padre-hija. La construcción del concepto de tercero aparece con especial énfasis en el psicoanálisis y más precisamente en el psicoanálisis lacaniano. Al tercero se lo asemeja al lenguaje, al simbólico, al gran 'Otro', a la cultura, a la ley, o a su representante: la función paterna. La idea de tercero apunta a un elemento de la estructura, esencial a la vez para la estructuración del sujeto y para el mantenimiento del lazo social. La idea de tercero o tercio, no debe ser reducida a una persona, sino a una función, que en el caso de la mediación, es puesta en juego por la persona del mediador.

Con el incesto, la relación entre el padre y la hija no es una relación mediatizada por el Otro de la ley de la sociedad sino una relación dual mortífera en el que la participación de un tercero queda rezagada. El padre hace función, aquella por la cual encarna la ley y viene primeramente a hacer corte entre la niña y su madre pero que finalmente regula el deseo y el goce de la pequeña, entre este padre y su hija no opera ese corte necesario para la estructuración de la niña como sujeto individual y su inscripción en la ley y la sociedad. De esta manera, la niña es mantenida en una relación mortífera con uno de sus padres, al encontrarse nuevamente en una relación dual tan destructiva con el padre. Como se dijo ya, el padre incestuoso se rehúsa a que un tercero venga a hacer corte en la relación con su hija, rechaza en última instancia ese tercero que representa la sociedad, la ley, es la abolición de la distancia entre generaciones al servicio de la pulsión de muerte. Es de este modo que se entiende lo fundamental que es la implicación de un tercero en esta relación, de hecho, el develamiento del 
incesto por parte de la niña, no es más que la búsqueda a gritos de ese tercero que venga a enunciar la ley y frenar la situación de abuso.

En el proceso de mediación, la persona del mediador vendría a ocupar el lugar simbólico de ese tercero, el mediador es ese representante del gran Otro, función paterna que viene a enunciar, dentro de un ámbito legal, y a inscribir por primera vez al padre y a la niña en un registro hasta ahora desconocido para ellos: la Ley de prohibición del incesto, fundamental para la convivencia social.

\section{La mediación penal: oportunidad de rehabilitación para el autor del crimen, reparación psíquica para la victima y el regreso a la conviven- cia familiar y social bajo una nueva norma}

La mediación penal ofrece la oportunidad al padre que comete incesto de obtener, aunque no se lo hubiese propuesto inicialmente, una exacta visión de las consecuencias de su delito y del sufrimiento causado a su hija y así la posibilidad de hacerse responsable de sus actos. Al hacerse responsable del incesto, el padre asume un lugar diferente dentro del conflicto e inicia el camino de su recuperación. Uno de los objetivos más importantes de la mediación es la posibilidad para este padre "de restaurarse, no solo en el plan imaginario sino también simbólico, o por lo menos de actuar de manera estructurante para él" (Dupret, 2003: 92). La mediación penal busca la resocialización del padre abusador, es decir que después de cierto tiempo y dentro de un proceso de mediación acompañado por medidas socio-educativas y psicológicas como parte del acuerdo, pueda trabajar acerca de lo que lo llevó a cometer el abuso, iniciar un proceso de rehabilitación y volver a ser parte activa de la sociedad. Por otro lado, parte esencial de la mediación con el padre abusador, es la reparación de éste a la víctima. La reparación es un modo de hacer algo por su hija que ella y los demás reconozcan como útil, valioso y un esfuerzo por su parte. "La reparación ofrece una solución nueva y diferente del pasaje al acto o de la actuación impulsiva, ya que necesita ser elaborada y reflexionada, abriendo el paso a la creatividad del pensamiento y al placer que conlleva" (Dupret, 2003: 88), de esta manera permitir al padre volver a creer en sus potencialidades reparadoras y no centrarse únicamente en el daño que causó. La reparación implica primero 
el aspecto subjetivo de enmendar lo que uno mismo ha dañado, obviamente, cuando uno ha comprendido y aceptado lo que ha dañado, en este sentido es en primer lugar productiva para el sujeto y en segundo término para la víctima.

En cuanto a la víctima, sólo añadiremos que la mediación penal, al responsabilizar al padre de sus actos, produce en ella la posibilidad de un resarcimiento sumado a la posibilidad de obtener respuestas del porqué del abuso en su contra y de la personalidad y entorno de su padre a fin de iniciar una reparación psíquica del incesto. Por otra parte, esta reparación psíquica se hace posible a partir de los acuerdos con que la mediación finaliza, acuerdos que han sido elaborados tomando muy en cuenta sus necesidades y seguridad, estas medidas son generalmente de protección tanto física como emocional para ella, y socioeducativas y psicológicas para el padre, y deben ser cumplidas en su totalidad so pena de iniciar o re-iniciar un proceso jurídico-penal regular. La mediación penal, intenta que las partes involucradas, recreen y logren comprender el porqué de sus acciones y lleguen al fin, al justo remedio que les permita reponer la armonía social, "el regreso a esa armonía que el delito había conculcado con violencia" (Neuman, 2005: prologo). En fin, el sentido último de una mediación penal en caso de incesto es llegar a recomponer las relaciones sociales o generar nuevas relaciones entre las partes del conflicto, tarea que no resulta sencilla pero tampoco imposible.

La mediación penal, cuando alcanza su objetivo, logra la readaptación social de los involucrados. Al padre como ya vimos, le otorga la posibilidad de rehabilitación y de convertirse en un sujeto responsable y protector capaz de ocupar un nuevo lugar dentro de la familia y participar en la construcción subjetiva de sus hijos, mientras que a la niña, víctima del abuso, le otorga la posibilidad de elaborar el abuso, hacerlo parte de su historia, pero sobre todo de recrear un vinculo sano y positivo con su padre, y a la familia ser un sistema estructurado y ético, diferenciado e inscrito en el orden social.

\section{Riesgos y límites de una mediación penal en caso de incesto}

Como todo proceso, la mediación penal presentaría riesgos y limites que son necesarios tomar en cuenta, entre ellos es que ésta sea tomada, sobre todo por el padre, como una salida fácil a la situación de incesto y utilizada para 
evitar la prisión, de esta manera la mediación no permitiría elaborar los hechos, ni responsabilizarlo de sus acciones. Por otra parte, una mediación penal no puede ser realizada indistintamente a todos los casos de incesto, de hecho, una mediación penal no sería posible, y por el contrario sería muy riesgosa, en casos en los que el padre abusador tenga una estructura psicótica o de tipo perversa, situaciones en las cuales, la inscripción en la ley y en la dialéctica de la palabra que pretende una mediación, no serían posibles. Otro de los riesgos más importantes de una mediación penal en caso de incesto es que luego de concluido el proceso con la firma del acuerdo final de mediación, no se realice un seguimiento posterior, es decir que no se compruebe que todas las condiciones y planteamientos del acuerdo de mediación se estén cumpliendo. Igualmente, se puede tomar a la mediación como una negociación:

...la mediación tiene como meta el restablecimiento del diálogo y del lazo social entre los sujetos, una negociación remite a una repartición de bienes bajo la forma de "yo te doy, tu me das". Desde luego el acento es muy distinto, considerando que la mediación crea un espacio de interlocución entre las personas y se centra en la relación simbólica, mientras que la negociación juega con objetos (Dupret, 2005: 5).

El incesto es la situación más difícil de tratar dentro de los abusos sexuales en general, ya que esta situación está sometida a las más grandes resistencias incluso entre los profesionales que están continuamente frente a este tipo de casos, Por este motivo es importante recalcar la importancia de la calidad ética e imparcialidad del mediador al trabajar con este tipo de delitos sexuales.

\section{Bibliografía}

\section{Textos y Libros}

ARÉCHAGA, Patricia y otros. (2005), La trama de papel: Sobre el proceso de mediación, los conflictos y la mediación penal. Buenos Aires: Ed. Galerna. 
CRIVILLÉ. A. (1996), L’inceste, comprendre pour intervenir. Paris, Ed. Enfances Clinique.

DUPRET, Marie-Astrid (2005), Delincuencia juvenil, hacia una política de rehabilitación. Quito: Ed. Abya Yala.

DUPRET, Marie-Astrid. (2003) Violencias familiares, modelos de intervención y resolución alternativa de conflictos. Las apuestas de la mediación. Ponencia presentada en el primer seminario internacional "Derechos de la niñez". UPS. Ecuador, Enero 2003.

GABEL, Marceline (2007), Les enfants victimes d'abus sexuels. Ed. P.U.F.

HAESEVOETS, Yves- Hiram (2008), L'enfant victime d'inceste. De la séduction traumatique a la violence sexuelle. 2 eme Edition Oxalis.

LE NAIL, Philippe (2008), Une experience de cours d'asises sur le phenomene de repetition » Le coq-Heron \#195, Toulouse, France: Ed. Eres.

NEUMAN, Elías (2005), Mediación penal. Buenos Aires: Ed. Universidad.

\section{Leyes:}

Ecuador. Leyes, estatutos, etcétera, Código Penal, Legislación Conexa, Concordancia, Quito 2008

Ecuador, Leyes, estatutos, etcétera, Código de la Niñez y Adolescencia, Legislación Conexa y Concordancia, Jurisprudencia, Quito 2007.

\section{Internet:}

Patria potestad. En internet: http:// es.wikipedia.org/wiki/patria_potestad. (Fecha de acceso: 10 de marzo de 2009)

Envío 28 de septiembre/2010 - aceptación 10 de noviembre/2010 